\title{
Quantitative analysis of influencing factors of single vessel maintenance standard cost
}

\author{
TANG Haoning ${ }^{1,2}$, LIANG Xin ${ }^{1, *}$ \\ ${ }^{1}$ Department of Management Engineering and Equipment Economy, Naval University of Engineering, Wuhan 430033, China \\ ${ }^{2}$ Military training base of Xinjiang Armed Police Corps, Urumqi, Xinjiang 830099, China
}

\begin{abstract}
Ship equipment maintenance fee of the single standard funds under the influence of many factors, in order to analyse the ship maintenance fee standard for each single loading factors influence the size of paper from two aspects: the ship itself and using the environment of ship cost, displacement, use fixed number of year, the price level, service environment, the use frequency of six index quantification, the factors which influence on factors affecting the characteristics of the mutual influence and mutual restriction between the measures, using the index of conflict and contrast between the strength of give attention to two or more things CRITIC method for quantitative analysis. The results show that the six influencing factors are in order from large to small: price level, service life, service frequency, service environment, ship cost, displacement.
\end{abstract}

\section{Introduction}

Ship equipment maintenance and management fee single installation standard expenses refer to the expenses used for basic and routine maintenance, repair, and management of ship equipment during a year. The randomness of occurrence is small, and the expenses of expenses follow certain rules. Therefore, it is possible to carry out a quantitative analysis of the factors influencing the expenditures of the ship's equipment maintenance management fee during a year to further grasp the regular expenditure of the ship's equipment maintenance management fee. The calculation of expenditures and the adjustment of the single installation standard of ship equipment maintenance and management fees are of great significance.

\section{Influencing factors of ship equipment maintenance and management fees}

There are many factors that affect the standard cost of the maintenance and management fees of ship equipment. For example, different ship types will directly affect the daily expenses of ship equipment maintenance and management fees according to different ship functions, power devices, and weapon configurations. Since the types of ships are not easy to quantify, the types of ships can be decomposed into easily quantifiable indicators such as ship cost and displacement for analysis. This article will select some relatively easy to quantify influencing factors for analysis, and divide these influencing factors into two categories: ship equipment itself and use environment factors. The factors of ship equipment include ship construction cost, displacement, service life, etc. These factors are only related to the properties of ship equipment, and do not change with changes in the use environment; while the use environment factors include ship service environment, frequency of use, and price level Wait[1].

\subsection{Influencing factors of ship equipment itself}

\subsubsection{Shipbuilding cost}

The cost of a ship is mainly composed of hardware prices and non-hardware prices. Hardware prices refer to the prices of various equipment and materials; non-hardware prices are mainly composed of labour costs such as working hours, consumables, military special expenses, unforeseen expenses and profits and other composition. To a certain extent, the cost of shipbuilding directly reflects the combat effectiveness of ship equipment. For example, the cost of military auxiliary ships is often lower than that of combat ships, which directly affects the daily expenses of ship equipment maintenance and management fees. Ship equipment is often expensive due to advanced equipment, scarcity of materials, high technical performance requirements, difficulty in construction, and long construction hours. These reasons also make such ships more expensive in daily maintenance and repair.

\subsubsection{Displacement}

Displacement is an important indicator used to indicate the size of the ship, and refers to the quality of the water discharged when the ship is fully loaded. The larger the 
displacement, it usually means that the ship has a larger weight and volume, requires a more powerful power system, and is equipped with higher performance weapons. In order to ensure that the ship meets the required technical status and combat performance, the repair works, materials and labor involved in the repair process are larger, and therefore more maintenance support funds need to be invested.

\subsubsection{Service life}

The service life refers to the time when the ship's equipment enters service. In the current regulations, the same type of ship equipment with different service life is applicable to the same funding standard, and the impact of ship equipment service life on the maintenance and management fees of ship equipment is not considered. In fact, as the service life increases, the standard funding for ship equipment that year may not be able to meet its maintenance and support needs, and it needs to be adjusted from other single-installed items; and for new ship equipment, the standard funding may appear A large amount of surplus has caused a waste of military expenditure. In fact, the remaining service life of ship equipment will directly affect the expenditure of ship equipment maintenance and management fees.

The life of ship equipment includes natural life, economic life and technical life. Technical life and economic life are often shorter than natural life. When the service life of ship equipment is shorter than economic life or technical life, with the artificial consumption and natural wear and tear of ship equipment, the probability of equipment failure will increase, and ship equipment maintenance and management costs will increase accordingly. However, there is not always a positive correlation between the service life of ship equipment and the maintenance and management fees of ship equipment. Once the service life of the ship equipment reaches the economic life, the corresponding economic benefits cannot be obtained; or the service life reaches the technical life, the ship When the ship's equipment is replaced by more advanced new equipment and is eliminated and scrapped, even if the ship's equipment fails to meet the production requirements or the production efficiency is very low after maintenance, the ship's equipment loses the need for maintenance, that is, the maintenance management cost at this time is 0 .

\subsection{Use environmental factors}

\subsubsection{Price level}

Ship equipment maintenance and management costs are measured in currency, and will inevitably be directly affected by price changes. The material cost and man-hour cost of ship equipment are the two main components of maintenance and management cost, and price changes have the greatest and most direct impact on man-hour cost and material cost. When the price level is high, the price of ship equipment maintenance equipment, spare parts, and maintenance equipment will increase, and the wages of maintenance personnel will also increase, resulting in a substantial increase in ship equipment maintenance management costs. Therefore, ship equipment maintenance costs are greatly affected by price changes. Due to the unbalanced economic development in various regions and other social factors, the price levels in different regions are also different, which also has a significant impact on maintenance and management fees. It can be seen from the statistics of the unit price of ship equipment maintenance for man-hours that the maintenance and management costs of economically developed areas are higher than those of relatively backward areas.

\subsubsection{Service environment}

The service environment of ships includes marine environment and atmospheric environment[2]. The marine environment refers to the sea area where the ship equipment has been trained for a long time. Its elements include sea salinity, temperature, $\mathrm{pH}$, dissolved oxygen, etc.; the atmospheric environment refers to the maritime climate environment where the ship is in service, and its elements include atmospheric temperature, humidity and precipitation Wait. The service environment of ship equipment is a very complex and corrosive environment. my country has a large sea area with a large difference in climate between north and south. The climate in the south is humid and the temperature difference is small; the climate in the north is dry and the temperature difference is large, which leads to ship corrosion in different service environments. The rates are not the same, which directly affects the service life and maintenance frequency of ship equipment, which further affects the expenditure of ship equipment maintenance management fees. In addition, the relatively harsh natural environment of Nansha islands and reefs has increased the difficulty and intensity of daily maintenance and repair of ship equipment, thereby increasing the maintenance cost of ship equipment.

\subsubsection{Frequency of use}

Due to the different nature of the units, different units have different functions and tasks, even for the same type of ship equipment, the frequency of use is not the same. The probability of ship equipment failure will increase as the frequency of use of ship equipment increases, resulting in an increase in ship equipment maintenance and management costs. However, as the frequency of use increases, the skills of users and the level of support of maintenance personnel will correspondingly increase, making the growth rate of ship equipment maintenance management fees gradually slow. 


\section{Quantitative analysis of influencing factors}

\subsection{Quantification of evaluation indicators}

As mentioned above, a qualitative analysis has been carried out on the factors affecting the ship equipment maintenance management cost and the standard cost of the single installation. This article will select the corresponding evaluation indicators for quantitative analysis: the cost of the ship's equipment is used as the evaluation indicator; the ship's equipment displacement Relevant data can be directly obtained through the specific model of ship equipment to determine its tonnage; considering the difference between the service life of different types of ship equipment, the service life of the ship equipment is compared with the natural life, economic life and technical life. The ratio of the minimum value is used as an evaluation indicator; there are many indicators that characterize the price level, because the general price index has an explanatory effect on the fluctuation range of all commodities, so this article selects the general price index to represent price changes; the service environment selects the corrosion rate as a quantitative indicator; Use the amount of troop tasks as an evaluation index for frequency of use.

\subsection{CRITIC empowerment method}

Ship equipment single installation maintenance management expenses are affected by many factors. These influencing factors have a very complicated nonlinear relationship with the ship equipment maintenance management cost single installation standard expenses. Each influencing factor needs to be affected according to the degree of influence of each influencing factor. For weighting, determine the degree of influence of each influencing factor according to the difference in weight. Because the various influencing factors are not completely independent, but influence and restrict each other. For example, the cost of ship equipment with large displacement is often higher; the cost of ship equipment will fluctuate with changes in prices; the service environment and frequency of use of ship equipment will directly affect its service life and so on. Combining with the CRITIC weighting method, comprehensively consider the influence of index variation on the weight and the characteristics of the conflict between each evaluation index. Therefore, this paper selects the CRITIC weighting method to analyse the factors affecting the standard expenditure of the single-installation maintenance management cost of ship equipment. Empowerment.

The CRITIC weighting method is a better objective weighting method proposed by Diakoulaki[3]. It is mainly based on two objective factors to determine the objective weights of indicators: contrast intensity and conflict. The contrast strength is expressed in the form of standard deviation, and the size of the standard deviation indicates the size of the difference in the value of each scheme within the same indicator. That is, the greater the standard deviation, the greater the value difference between the various programs, the greater the contrast intensity. Conflict is expressed by the correlation coefficient of indicators, based on the correlation between indicators. That is, the stronger the correlation between the indicators, the larger the correlation coefficient and the lower the conflict. If there is a strong positive correlation between the two indicators, it means that the conflict between the two indicators is low and the correlation coefficient is larger.

The evaluation index weight is calculated according to the CRITIC weighting method, and the calculation steps are as follows:

Step 1 Collect raw data and select evaluation indicators for quantification.

Step 2 Dimensionless processing. Assume that the original data has $i$ individuals and $j$ type indicators. Since the dimensions of different indicators are different, firstly, each indicator is processed without dimension. If standardization is used, the standard deviations all become 1, that is, the standard deviations of all indicators are exactly the same, which makes the volatility indicators meaningless. Therefore, the larger the number, the better to use the forward processing, and the smaller the better to use the reverse processing to ensure the same directionality of the indicators. The processing formulas are as follows:

Forward processing formula:

$$
r_{i j}=\frac{f_{i j}-\min _{i} f_{i j}}{\max _{i} f_{i j}-\min _{i} f_{i j}}
$$

Reverse processing formula:

$$
r_{i j}=\frac{\max _{i} f_{i j}-f_{i j}}{\max _{i} f_{i j}-\min _{i} f_{i j}}
$$

Step 3 Calculate the contrast intensity. Let $\rho_{i}$ denote the intensity of contrast between the $\mathrm{j}$ index and other indexes, expressed in the form of coefficient of variation instead of standard deviation:

$$
\rho_{\mathrm{j}}=\frac{\sigma_{j}}{\bar{X}_{j}}, \text { among } \bar{X}_{j}=\frac{1}{\mathrm{n}} \sum_{i=1}^{n} X_{i j}
$$

Step 4 Calculate the correlation coefficient. Assuming that $\mathrm{j}$ and $\mathrm{k}$ are two different types of indicators, $c_{j k}$ represents the degree of conflict between indicator $\mathrm{j}$ and indicator $\mathrm{k}$ :

$$
c_{j k}=\sum_{k=1}^{n}\left(1-\left|r_{j k}\right|\right)
$$

Among them, $r_{j k}$ is the correlation coefficient between $\mathrm{j}$ and $\mathrm{k}$ :

$$
r_{j k}=\frac{\sum(j-\bar{j})(k-\bar{k})}{\sqrt{\sum(j-\bar{j})^{2} \sum(k-\bar{k})^{2}}}
$$

Step 5 Calculate the amount of information and weight.

$$
I_{j}=\rho_{i} c_{j k}
$$

$\mathrm{I}_{\mathrm{j}}$ represents the amount of information contained in index $\mathrm{j}$. The larger $\mathrm{I}_{j}$, the greater the amount of information contained in the $\mathrm{j}$ evaluation index, the greater the relative importance of the index, and the greater the weight assigned. Therefore, the objective weight $\omega_{j}$ of the $\mathrm{j}$ index is expressed as: 


$$
\omega_{\mathrm{j}}=\frac{I_{j}}{\sum_{j=1}^{n} I_{j}}
$$

The index data of each influencing factor collected for the maintenance and management cost of ship equipment is shown in Table 1.

\subsection{Application analysis}

\subsubsection{Quantitative indicators of influencing factors}

Table1. Quantitative indicators of various influencing factors of ship equipment maintenance and management fees

\begin{tabular}{|c|c|c|c|c|c|c|}
\hline & $\begin{array}{c}\text { Purchasing } \\
\text { costs }\end{array}$ & $\begin{array}{c}\text { Drainage } \\
\text { volume }\end{array}$ & $\begin{array}{c}\text { Percentage of service } \\
\text { life }\end{array}$ & $\begin{array}{c}\text { Price } \\
\text { index }\end{array}$ & $\begin{array}{c}\text { Corrosion } \\
\text { rate }\end{array}$ & $\begin{array}{c}\text { Task } \\
\text { volume }\end{array}$ \\
\hline A & 7000 & 4200 & 0.38 & 108 & 0.03 & 1.2 \\
\hline B & 7000 & 4400 & 0.31 & 108 & 0.01 & 1.4 \\
\hline C & 6000 & 3650 & 0.33 & 114 & 0.1 & 1.2 \\
\hline D & 6000 & 4100 & 0.36 & 114 & 0.08 & 1.5 \\
\hline E & 4000 & 2800 & 0.63 & 114 & 0.04 & 1.5 \\
\hline F & 5000 & 3300 & 0.56 & 108 & 0.09 & 1.5 \\
\hline G & 3700 & 2000 & 0.38 & 125 & 0.03 & 1.3 \\
\hline H & 3000 & 3700 & 0.38 & 125 & 0.07 & 1.3 \\
\hline I & 2500 & 2200 & 0.29 & 125 & 0.02 & 1.2 \\
\hline
\end{tabular}

(In this example, $\mathrm{i}=9, \mathrm{j}=6$ )

\subsubsection{Calculate the weight of influencing factors}

In this example, the 6 types of indicators have the same direction, so all indicators are processed in the normal direction. After the dimensionless processing of formula (1), the matrix $\mathrm{M}$ is obtained as follows:

$$
M=\left[\begin{array}{cccccc}
1 & 0.9167 & 0.1837 & 0 & 0.2222 & 0 \\
1 & 1 & 0.0408 & 0 & 0 & 0.6667 \\
0.7778 & 0.6875 & 0.0816 & 0.3529 & 1 & 0 \\
0.7778 & 0.8750 & 0.1429 & 0.3529 & 0.7778 & 1 \\
0.3333 & 0.3333 & 0.6939 & 0.3529 & 0.3333 & 1 \\
0.5556 & 0.5417 & 0.5510 & 0 & 0.8889 & 1 \\
0.2667 & 0 & 0.1837 & 1 & 0.2222 & 0.3333 \\
0.1111 & 0.7083 & 0.1837 & 1 & 0.6667 & 0.3333 \\
0 & 0.0833 & 0 & 1 & 0.1111 & 0
\end{array}\right]
$$

According to formulas (3)-(7), the standard deviations, correlation coefficients, conflicts, information volume and weights of each influencing factor index of the ship equipment maintenance management cost single installation standard expenditure are shown in Tables 2 and 3.

Table2. Correlation coefficients (r) between the various influencing factors of the standard cost of ship equipment maintenance and management fees

\begin{tabular}{rcccccc}
\hline Index & $\mathbf{1}$ & $\mathbf{2}$ & $\mathbf{3}$ & $\mathbf{4}$ & $\mathbf{5}$ & $\mathbf{6}$ \\
\hline $\mathbf{1}$ & 1.0000 & 0.7950 & -0.1393 & -0.8562 & 0.0733 & 0.1029 \\
$\mathbf{2}$ & 0.7950 & 1.0000 & -0.1882 & -0.6756 & 0.2176 & 0.1360 \\
$\mathbf{3}$ & -0.1393 & -0.1882 & 1.0000 & -0.2880 & 0.2181 & 0.6514 \\
$\mathbf{4}$ & -0.8562 & -0.6756 & -0.2880 & 1.0000 & -0.1231 & -0.3725 \\
$\mathbf{5}$ & 0.0733 & 0.2176 & 0.2181 & -0.1231 & 1.0000 & 0.2015 \\
$\mathbf{6}$ & 0.1029 & 0.1360 & 0.6514 & -0.3725 & 0.2015 & 1.0000 \\
\hline
\end{tabular}

Table3. Standard deviation, conflict, amount of information

\begin{tabular}{|c|c|c|c|c|c|c|}
\hline & & & & & $J$ & \\
\hline & \multicolumn{6}{|c|}{0.66110 .59730 .96870 .91820 .73870 .8703} \\
\hline & \multicolumn{6}{|c|}{5.02434 .71534 .74607 .31544 .41274 .2807} \\
\hline & \multicolumn{6}{|c|}{3.32172 .81634 .59746 .71703 .25973 .7254} \\
\hline & \multicolumn{6}{|c|}{ 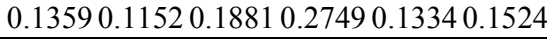 } \\
\hline
\end{tabular}
and weight of each influencing factor index

\subsubsection{Analysis of weighting results}

According to the calculation results of the weight of each influencing factor, $\omega_{4}>\omega_{3}>\omega_{6}>\omega_{1}>\omega_{5}>\omega_{2}$, that is, the degree of influence of each influencing factor is sorted from large to small: price level, service life, frequency of use, service environment, ship cost, Displacement. Among them, the weight of the influencing factors of ship equipment itself is $\omega_{1}+\omega_{2}+\omega_{3}=0.4392$, and the environmental influencing factors of ship equipment is $\omega_{4}+\omega_{5}+\omega_{6}=0.5608$. It can be seen that the use environment of ship equipment is more important for maintenance than its own attributes. The impact of singleinstalled standard expenses on management fees is greater. Therefore, when formulating or revising the ship equipment maintenance management fee single installation standard in the next step, it is necessary to focus on factors such as the current price level, the service life of the ship equipment, and the actual task volume of the army to ensure that the ship equipment maintenance management fee single installation standard fund Can adapt to the needs of current troops. 


\section{Concluding remarks}

This paper introduces the CRITIC weighting method, starting from the perspective of the correlation and comparison between the various influencing factors, and quantitatively analyses the influencing factors of the ship equipment maintenance and management cost single installation standard expenditure, evaluates and judges the degree of influence of each influencing factor. This paper provides a new way of thinking and direction for the next step to formulate or revise the ship equipment maintenance management fee billing standard.

However, this article only considers 6 influencing factors that are easy to quantify for analysis, and there are many influencing factors that are difficult to quantify, such as the ability and quality of maintenance personnel, the enthusiasm of equipment financial personnel for financial management, the advanced level of maintenance thinking, and the efficiency of equipment maintenance organization. The current technological environment, social environment, social policies, etc., need further study need further study to figure out the impact of these influencing factors on the standard expenditure of ship equipment maintenance and management fees. In addition, the CRITIC weighting method only makes comparative judgments based on the relationship between various influencing factors, and is not related to the equipment maintenance and management costs incurred by actual ship equipment. The next step needs to be improved on this basis.

I would like to thank my supervisor Liang Xin for giving timely and careful advice on the difficulties and doubts I encountered during the process of writing the thesis, and put forward many helpful suggestions for improvement. In addition, I would also like to thank my classmates for giving me great inspiration in the writing of the paper, and also to the authors of reference documents, who have given me a good starting point for the subject research through their articles.

\section{References}

1. Cao Huizhi, Chen Zedong, Niu Junfeng, Yang Chao, Shan Changhua. Life Cycle Cost Technology and Application(2012)

2. Yang Guangfu, Xing Huange, Qiu Dafu. Equipment Environmental Engineering,14(05): 86-92.(2017)

3. Diakoulakai D,Mavrotas G,Papayannakis L.Com puters \& Operations Research,22(7).(1995) 